INVITED 2008 CARROLL

D. Clark Lecturer

AT THE

UNIVERSITY OF KANSAS 



\title{
INTERVIEW WITH \\ BRUCE WeSTERN
}

\author{
PREPARED BY \\ ADA VAN ROEKEL-HUGHES \\ POOYA NADERI - FIRST INTERVIEWER \\ ROBERT HUGHES - SECOND INTERVIEWER
}

Naderi: First of all, welcome. We're really glad to have you. My first question actually deals with a concept that I came across in one of your books, which was collateral consequences. And I was curious if you could kind of elaborate on the meanings and dimensions of collateral consequences with respect to continuing racial and education disparities in imprisonment. Since initially putting this concept out there, are there newer collateral consequences that you've identified or other areas where this has affected families and communities beyond those that you initially outlined in some of your work.

Western: Yeah. So the term, I think the term collateral consequences have been used in two slightly different ways by researchers who are interested in the social consequences of imprisonment. One meaning is a narrow legal meaning and that meaning describes the legal disabilities that flow from having a criminal record, so restricted access to licensed occupations, restricted access to certain welfare benefits or federal programs. And then the broader idea of collateral consequences was actually used by, used first, that I know of, by John Hagan and this broader idea describes all the social consequences that might flow from serving time in prison, so lost earnings, reduced employment in the labor market for formally incarcerated people, disrupted families. And those two outcomes - effects on families and effects on employment - are concentrated on in my book, but I think we could multiply the list of those collateral consequences significantly. You know, we could think about the effects on health, the effects on children of incarcerated parents. This formulation 
of collateral consequences has made us think about the effects on individuals, but we could probably broaden the idea further to think about the negative social consequences for communities in which incarceration is heavily concentrated. I think this whole research program is just in its infancy. We still don't know very much about several of those topics that I listed. But I see those as being probably the most important.

Naderi: The second question that I have for you is related to this term that David Carven came up with, mass imprisonment. Although you've touched on this, I'm just curious, in your estimation, is mass imprisonment a self-defeating strategy? And I know that this term, self-defeating strategy, has been thrown out there [in debates if] that's the case or not. But in your view?

Western: I think that's the implication of research on collateral consequences actually because if we have an effort at crime control that makes it harder for people to find jobs, for people to integrate into their family lives and we know that employment and stable family relationships are the keys to criminal desistance, then this particular effort at crime control is ultimately sowing the seeds for more crime in the long run. And I think we could also extend that argument to the next generation. So I think there's a good argument that this is a self-defeating strategy for crime control. At a macro-level, if we think of highly functioning societies as being cohesive and well-integrated, a mass imprisonment, which is so heavily concentrated in a small number of social groups, that has the consequence of dividing societies, rather than unifying them. I think in that macro-social sense, mass imprisonment is a selfdefeating strategy for crime control.

Naderi: My last question, before I hand things over to Robert, is related to, well, I'm asking you to extrapolate a little bit and one of the thing that I find interesting is not just the social context of the US for imprisonment, but how you might apply these consequences for nations that have different targets of incarceration, for instance, based on political or religious affiliation or something along those lines. So my question is would you expect to find a similar disruption in the life course in other, like totalitarian systems, for example, 
for families, for similar implications for marriages and these other institutions that they might share with us. Generally, how would you approach that or what feelings do you have about other nations with respect to this.

Western: I think these micro-level effect of incarceration on individual draws on their individual earnings, on patterns of family life and so on, I think these are very generalizable because the groups that are exposed to the highest risk of incarceration are young men and so this is an intervention that is happening in a certain point in the life course where in a very general way, across societies, young men are typically moving into the labor market and starting families. I think the generality of these kinds of effects would be limited by the kinds of experiences people have in prison. In America, prison terms tend to be quite long, prisons are often located in far-flung places a long way from the communities that supply most of the prisoners, and over the last 30 years, support for rehabilitated programming has contracted, so there's a lot of vitalness in prison. People spend a lot of their time doing nothing. If the experience of incarceration was quite brief, if incarceration was oriented to the re-integration of people coming out into their societies, then I think you could see different kinds of effects. We look at other countries in which incarceration rates are extremely high, in South Africa, in the former Soviet Republics, incarceration is not particularly rehabilitatively oriented, so I think we could expect similar effects in those settings as we see in the United States.

Hughes: Alright, the fourth question that we have for you today concerns color-blind racism. And since the civil-rights era, the discourse of color-blind racism has argued, and continues to argue, that race is no longer relevant, discrimination is a thing of the past, and the achievement gap between blacks and whites can be explained by cultural differences and individual choices. How do your findings uncover the systematic discrimination of blacks and the sedimentation of racial inequality over generations?

Western: It's a good question. So I think of discrimination in a very narrow way, almost in a legalistic way that we might see in any discrimination law, so if two cases come up in a court and they 
have the same facts and you've got a black defendant and a white defendant and if a judge treats the black defendant more harshly, then we can say that differential treatment is discrimination. The growth of the penal system, which has been characterized by massive racial disparity, African Americans are seven-to-one times more likely to go to prison than whites, a far higher social disparity than social indicators we can think of. I think of the growth of the penal system not so much as a manifestation of discrimination, but as institutionalization of racial difference, an institutionalized probably better, an institutionalization of racial hierarchy and the law, which is color-blind on its face, has been written and enforced in such a way that it imposed a massively disparate burden on African Americans, particularly those with little schooling. And in a way, I think this is very much a post-civil rights phenomenon because the impulse that's driving it is not the kind of discrimination that's contemplated by anti-discrimination law, it's as much a penalization, a combination of urban poverty for socially threatening population and so this is how racial inequality, or this is one mechanism of how racial inequality is being produced in the post-civil rights era in which discrimination of the kind that's contemplated by antidiscrimination law is not the main driver.

Hughes: Shifting gears here to a methodological question, much of your data analysis, if not all-I'm not totally familiar with all of your work - utilizes a Bayesian statistical approach. Many qualitative scholars are unfamiliar with frequentist data analysis let alone this newer Bayesian perspective. And I was wondering first, how does this approach differ from the more commonly utilized frequentist method and how does your choice to use the Bayesian approach influence the interpretation of your data?

Western: The base in statistics differs in both foundational and superficial ways from traditional frequentist statistics. At its foundation, the concept of probability, which is the foundational concept of all statistics, the concept of probability is very different from the frequentist approach and the concept of probability in the freqentist approach is the role that frequency in a hypothetically large number of trials, so if we're flipping a coin, what's the prob- 
ability that it will come up heads, well, if we were to do that 10,000 times and it came up heads 5,000 times, which say the probability of heads is .5 and that's what happens in a large number of trials. In the Bayesian approach, the concept of probability is subjective and that means we are subjectively uncertain about whether we're going to get a head or a tail and we quantify that uncertainty by a number between 0 and 1 -that's what a probability is construed to be - and if we're equally uncertain about a head or a tail, we would say, it's rational for us to say, the probability of heads is .5. So it's not this idea of a large number of repeated trails, so that's the foundational difference. The kinds of information that, it turns out that this idea has a very significant implications to how we do empirical research because the kinds of information that's used in an analysis and not just the data that we observe, but our subjective beliefs about what we expect, what we expect to observe and one way of viewing Bayesian statistics is as a method that describes how our prior beliefs are updated by data, how our prior beliefs are modified by data. I think we're all sort of Bayesians under the skin and what's important about the Bayesian approach is that this process by which our prior beliefs and opinions are modified by data is made transparent in the analysis and I think that's often inexplicit in a data analysis and the prior biases of the researcher are still there in the frequentist analysis, they're just not revealed to us, so it's the transparency of the Bayesian approach that's part of its appeal.

Hughes: Moving on, a major theme in American Sociology over the last few years has been making sociology more public. Do you consider your research on incarceration in the United States to fall within this category of public sociology and how are, or are you, trying to make your findings more public?

Western: When I started out on this project, so I started doing work in this area about 10 or 12 years ago now, and when I started out on this topic, I was very much what I thought of as a straight Weberian, where our job as social scientists is applying our methods to well-defined research questions to the extent that we wanted our work to have effects in the world only came into the process in our 
choice of research questions. And so the normative implications of the work were very circumscribed. As this project developed, my thinking about that issue has changed a lot actually. I think, of course, we choose the topics because we're invested in them in some way and our choice of topics often embodies a social critique, but I think as you look at the political and the policy field, it seems wrong to me that the expertise we acquire through our research shouldn't be involved in some way in informing the next step of trying to talk about politics and policy and that is something I've been very concerned about over the last few years. I've written a lot about policy and politics this past year and for people interested in this field, I think there's a lot we can do. We should be getting out into the field, we're studying a social setting that's extremely difficult to penetrate and it's designed to keep people removed from society. I think we should be trying to go into prisons in one way or another, and make them more transparent to society. I think they're ground so fantastically because they're largely invisible to us. So how can we do that? We can do that as researchers, we can try to do that in our teaching, I think we shouldn't fear political discussion and policy debates. It's an utterly radioactive political issue and elected officials have no interest in speaking up for those people who have been convicted of crimes. And yet a massive social injustice is being perpetrated by the growth of the penal system. I think if we can't apply our research to this problem, you know it's difficult to know who is going to call out the injustice in this case because those that are affected are so massively disempowered by it. And there are many things we can do: we can speak to public officials, get involved in the policy process, speak to policy makers, the people that run the prison system. There are many terrific people in the system and they're being charged with an impossible task and they are certainly by no means the enemy in the process and I think that we, as researchers, also need to understand what they're confronting as well.

Hughes: My last question, obviously research on incarceration rates invites serious policy implications, as you just discussed. What policy recommendations would address the inequality between blacks and whites as well as gaps in education, wealth, and employment? 
Western: So racial inequality in general?

\section{Hughes: Yes.}

Western: These are very profound and have been largely intractable inequalities especially for those in the bottom half of the education distribution, especially for those who have never been to college. I was at a conference on the Moynihan report last spring and it was striking. We're sort of revisiting the Moynihan report, which was written in 1965 and provided a diagnosis for black urban poverty, in particular, and racial disadvantage, more generally. And on a whole number of social indicators, things are now worse for African Americans than when Moynihan was writing and Moynihan's report was a call for national action. I think ultimately three problems seem fundamental that policy has to tackle. One is the problem of educational opportunity for African American kids in poor urban areas. The other is the problem of residential segregation, which is an incredibly tough problem. I think actually none of the policy instruments that we have used to reduce residential segregation have been successful. And the third problem is the very severe employment problems among young black men. They're the three things that the public policy needs to solve. I think there's a lot of attention and excitement given to early child interventions. I think that holds some promise. Segregation, as I said, I don't know the answer to that. Employment, I think will require policies that work on the demand side of the labor market as well the supply side, all of the emphasis has been on improving the skills and training and job readiness of African American men to the extent that there has been an emphasis on it in public policy. I think we should probably be thinking about employment programs, subsidized employment that helps build routines of steady work that can pass on benefits to families and communities and so on. I think those kind of demandside policies are not really in the public policy discourse at the moment, but I think we need something radical of that type to break up what has been just incredibly enduring inequality.

Hughes: Well, thank you so much.

Western: It was a pleasure. Terrific questions. 